\title{
Radiant heating rates and surface biology during the Arabian Sea Monsoon Experiment
}

\author{
Yaswant Pradhan $^{1,2}$, Mannil Mohan ${ }^{1}$, Debasis Sengupta ${ }^{3}$ \\ and Shailesh Nayak ${ }^{1}$ \\ ${ }^{1}$ Marine \& Water Resources Group, ISRO-Space Applications Centre, Ahmedabad 380 015, India \\ ${ }^{2}$ School of Earth, Ocean \& Environmental Sciences, University of Plymouth, Devon PL4 8AA, UK \\ ${ }^{3}$ Centre for Atmospheric \& Oceanic Science, Indian Institute of Science, Bangalore 560 012, India \\ E-mail: yaswant.pradhan@plymouth.ac.uk
}

Received 27 October 2004

Accepted for publication 12 January 2005

Published DD MMM 2005

Online at stacks.iop.org/JGE/2/1

\begin{abstract}
Radiometric observations are carried out to estimate the net shortwave solar radiation in the upper ocean during the Arabian Sea Monsoon Experiment Phase II (ARMEX-II). Radiant heating rates in the Arabian Sea Warm Pool (ASWP) region from in situ radiometric measurements are presented for the first time. The estimated shortwave fluxes $(300-700 \mathrm{~nm})$ from the observed data are 101, 62, 40 and $29 \mathrm{~W} \mathrm{~m}^{-2}$ at 10, 20, 30 and $40 \mathrm{~m}$ depths respectively. About $5 \%$ of the surface light reaches below $50 \mathrm{~m}$. Heating of the water column by penetrating solar radiation is substantial and estimated to be $0.18,0.11,0.08$ and $0.07{ }^{\circ} \mathrm{C} \mathrm{day}^{-1}$ in the upper $10,20,30$ and $40 \mathrm{~m}$ respectively. Simultaneous observations from space-based sensors (SeaWiFS and IRS-P4 Ocean colour Monitor) show an increase in solar absorption in regions with enhanced concentration of biologically active constituents.
\end{abstract}

Q1 Keywords:

\section{Introduction}

Study of evolution of the Arabian Sea Warm Pool (ASWP) prior to the onset of southwest (summer) monsoon is one of the key objectives of the Arabian Sea Monsoon Experiment (ARMEX). It is expected to eventually lead to a better understanding of monsoon variability. The role of shortwave radiant heating in conjunction with biologically active constituents in the thermodynamics of the ASWP has been studied for the first time during ARMEX Phase II (ARMEX-II). The chlorophyll- $a$ (Chl-a) pigments in phytoplankton lead to strong optical attenuation (Smith and Baker 1978, Morel 1988). Therefore they can play a significant role in the upper ocean heat budget (Godfrey and Lindstrom 1989). An effort was made to understand the relationship between the sub-surface temperature of the ASWP, radiant heating rate due to shortwave flux and Chl- $a$ concentration over this domain. This paper demonstrates significant changes in the upper ocean heating rates and possible relationship with optically active bio-constituents using observations from cruise 190 of the research ship ORV Sagar Kanya (SK190) and Chl- $a$ concentration from remote sensing satellites (SeaWiFS and OCM).

\section{Data and methods}

Data from the SK190 cruise of ARMEX-II, conducted in the south-eastern Arabian Sea (figure 1) from 14 March to 10 April 2003, are used to study the evolution of the pre-monsoon warm pool. In situ measurements of upper-ocean optical, physical, biological and meteorological parameters were made from ORV Sagar Kanya during this cruise. The optical profiles were used to estimate the radiant heating rates in terms of net penetrating radiation over the $300-700 \mathrm{~nm}$ wavelength domain. During SK190, optical measurements could be made only from 14 to 23 March 2003 because of a telemetry problem between the profiler and deck unit. However, the spatial 


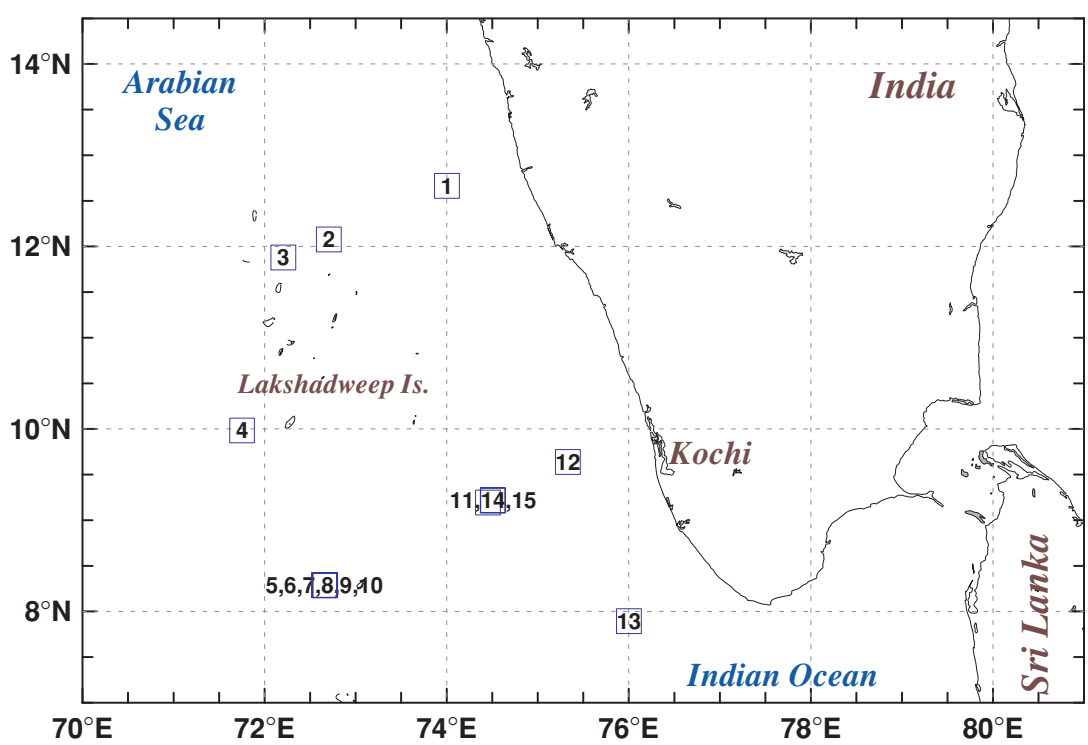

Figure 1. Locations (squares) for bio-optical measurements taken during ARMEX-II (14-23 March 2003).

Table 1. Station locations of concurrent bio-optical and physical measurement locations during SK190 (ref. figure 1).

\begin{tabular}{llllll}
\hline St. \# & $\begin{array}{l}\text { Position } \\
\left({ }^{\circ} \mathrm{E} /{ }^{\circ} \mathrm{N}\right)\end{array}$ & Date & St. \# & $\begin{array}{l}\text { Position } \\
\left({ }^{\circ} \mathrm{E} /{ }^{\circ} \mathrm{N}\right)\end{array}$ & Date \\
\hline 01 & $74.00 / 12.66$ & 14 March & 09 & $72.66 / 08.29$ & 18 March \\
02 & $72.70 / 12.07$ & 15 March & 10 & $72.66 / 08.28$ & 18 March \\
03 & $72.20 / 11.87$ & 15 March & 11 & $74.45 / 09.19$ & 19 March \\
04 & $71.75 / 09.98$ & 16 March & 12 & $75.33 / 09.63$ & 19 March \\
05 & $72.65 / 08.28$ & 17 March & 13 & $76.00 / 07.89$ & 20 March \\
06 & $72.66 / 08.28$ & 17 March & 14 & $74.50 / 09.21$ & 21 March \\
07 & $72.65 / 08.28$ & 17 March & 15 & $74.50 / 09.21$ & 23 March \\
08 & $72.65 / 08.28$ & 18 March & & \\
\hline
\end{tabular}

coverage of sampling during this short period is good (figure 1, table 1) and the data can be treated as representative of the ASWPwaters.

\subsection{Optical data in 400-700 $\mathrm{nm}$ range}

Optical radiometer/profilers, the SPMR (SeaWiFS Profiler Multi-channel Radiometer, or the profiler) and the SMSR (SeaWiFS Multi-channel Surface Reference, or the surface unit), deployed in the present experiment are designed and developed by Satlantic Inc., Canada. The profiler measures the upwelling radiance, $L_{u}(z, \lambda)$, and the downwelling irradiance, $E_{d}(z, \lambda)$, at seven discrete wavelengths (centred approximately at 412, 443, 490, 510, 555, 670 and $780 \mathrm{~nm}$ ). The surface unit measures the downwelling irradiance, $E_{s}\left(0^{+}, \lambda\right)$, just above the sea surface at these wavelengths. The nominal half-power bandwidth for each channel is $10 \mathrm{~nm}$ except for the last two $(20 \mathrm{~nm})$. Typical saturation of the radiance and irradiance signals are $20 \mu \mathrm{W} \mathrm{cm}{ }^{-2} \mathrm{~nm}^{-1} \mathrm{sr}^{-1}$ and $300 \mu \mathrm{W} \mathrm{cm} \mathrm{mm}^{-1}$, respectively. The detectors, made of Si-photodiodes, have spectrally corrected cosine response (for irradiance sensors) with noise equivalent irradiance (NEI) $\sim 5 \times 10^{-5} \mathrm{~W} \mathrm{~cm}^{-2} \mathrm{~nm}^{-1}$ and noise equivalent radiance (NER) $\sim 1 \times 10^{-6} \mathrm{~W} \mathrm{~cm}^{-2} \mathrm{~nm}^{-1} \mathrm{sr}^{-1}$. The system data rate in freefall mode is nearly $10 \mathrm{~Hz}$ with an optimized profiler speed of
$0.4-0.7 \mathrm{~m} \mathrm{~s}^{-1}$ where it collects approximately $10-12$ samples per metre depending on the free-fall speed of the profiler. Both systems are equipped with internal tilt and roll sensors for data quality checking during the casts. Optical data from individual profiles were excluded when the profiler tilt was greater than $5^{\circ}$. This reduces the uncertainty that could arise from the wave action and multiple reflections in the near surface waters. The radiometer units were deployed away from the vessel to avoid ship-induced perturbations and self-shadowing in the light field (Mueller and Austin 1993).

\subsection{Shortwave flux correction for $300-400 \mathrm{~nm}$}

The climatological mean (from Earth Radiation Budget Experiment, ERBE) incident shortwave radiation at the surface during March is $250-280 \mathrm{~W} \mathrm{~m}^{-2}$. The solar radiation incident at the surface lies in the wavelength range 300-3000 nm. For a clear sky tropical region, the net shortwave flux (over $300-3000 \mathrm{~nm}$ ) reaching the Earth's surface is about twice the radiative flux in the 300-700 $\mathrm{nm}$ range (Baker and Frouin 1987). The solar radiation in the wavelength range 300$700 \mathrm{~nm}$, however, is important in upper ocean heat balance because it penetrates into the sub-surface layers.

The total net shortwave flux at different layers beneath the surface must include the irradiances form 300 to $700 \mathrm{~nm}$. Although the contribution of radiation in the wavelength range greater than $700 \mathrm{~nm}$ is negligibly small below the first few centimetres from the sea surface, the contribution from 300 to $400 \mathrm{~nm}$ wavelength range is significant (figure 2). Since the Satlantic radiometer has only seven discrete bands in the $\sim 400-800 \mathrm{~nm}$ range, we performed a statistical analysis using hyper-spectral data (LI-COR, LI-1800) over the Arabian Sea (centred at $16^{\circ} 23^{\prime} \mathrm{N} / 71^{\circ} 22^{\prime} \mathrm{E}$ ) from a comparison in April 1997 to obtain the relationship between the $300-400 \mathrm{~nm}$ flux in relation to the total $300-700 \mathrm{~nm}$ flux. LI-COR is a portable spectro-radiometer, which measures hemispheric spectral irradiance (with cosine response) from $300 \mathrm{~nm}$ to $900 \mathrm{~nm}$ at $1 \mathrm{~nm}$ wavelength intervals. After examining 
(a) LI-COR Downwelling Irradiance, Ed(z)

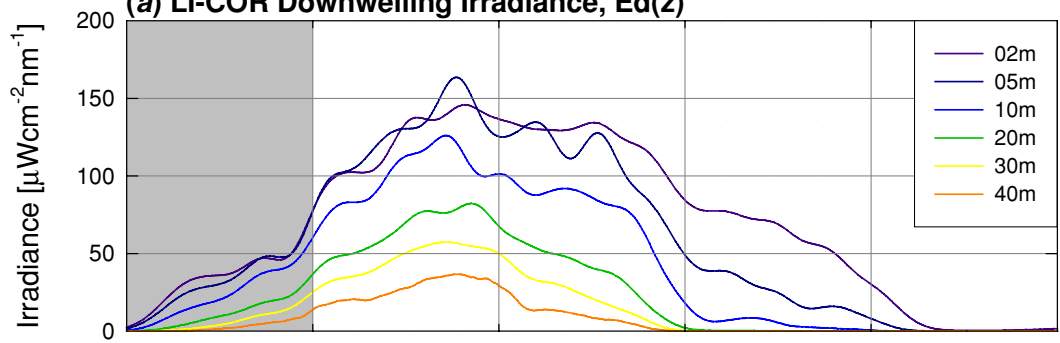

(b) LI-COR Upwelling irradiance, Eu(z)
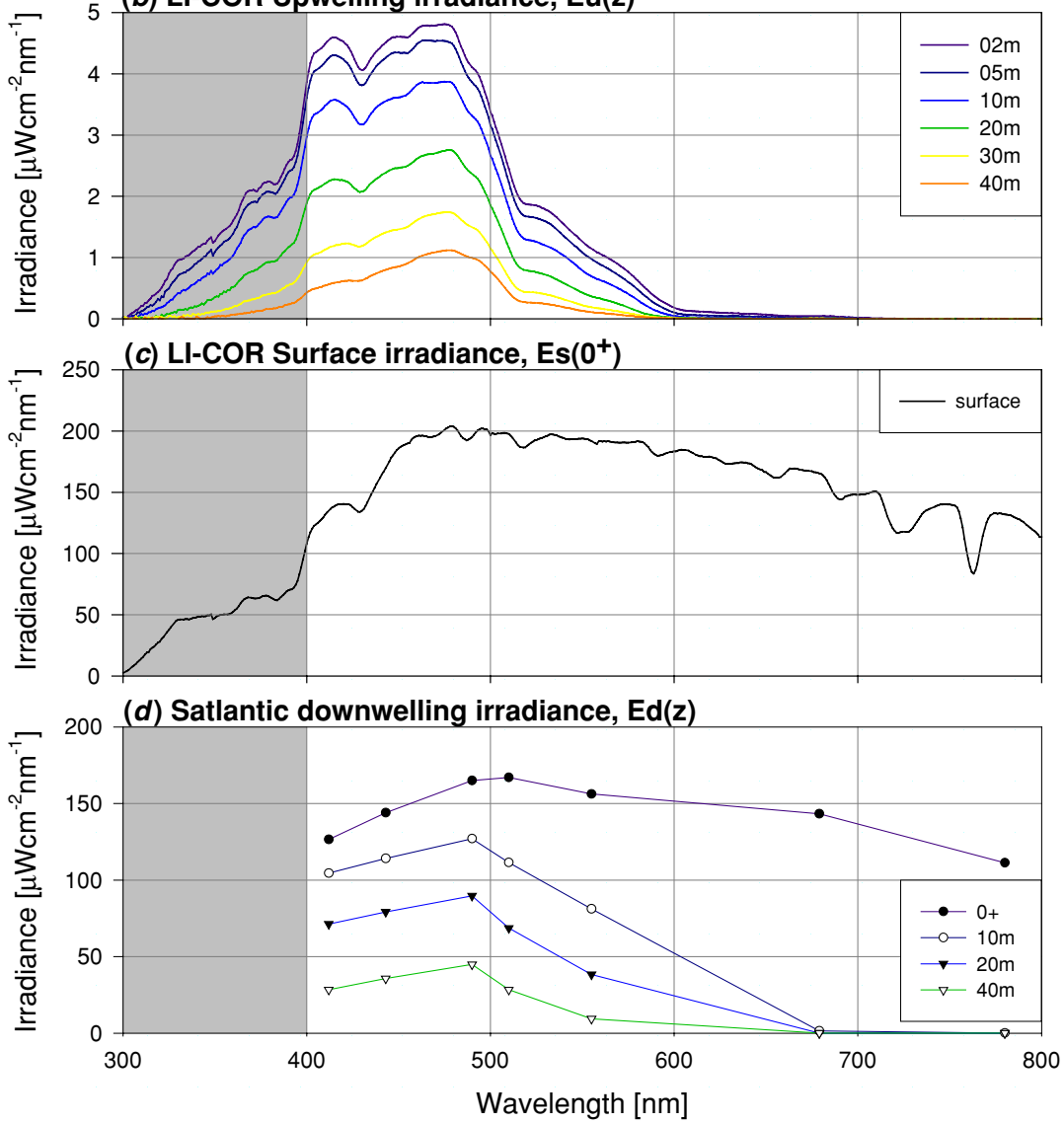

Figure 2. Sample LI-COR $(a)$ downwelling, $(b)$ upwelling and $(c)$ surface irradiance spectra taken during April 1997. The fractional irradiance over 300-400 nm (especially underwater) has significant contribution to the net shortwave (400-700 nm) irradiance. Panel (d) renders typical Satlantic profile showing changes in the downward irradiance spectrum with depth, on 18 March 2003 around 1300 hrs LST. Correction for the shadowed region is applied to all Satlantic profiles in this study. Note the rapid attenuation of energy in wavelengths greater than $600 \mathrm{~nm}$ below 10 metre depth (panels $(a)$ and $(d)$ ).

each profile (eight profiles at depths $02 \mathrm{~m}, 05 \mathrm{~m}, 10 \mathrm{~m}$, $20 \mathrm{~m}, 30 \mathrm{~m}, 40 \mathrm{~m}$ ) it was clear that the irradiance values beyond $700 \mathrm{~nm}$ are negligible below the sea surface due to a strong attenuation of longer wavelengths. The per cent contributions of irradiances over 300-400 nm range (per cent fractional flux) are estimated as a function of depth based on linear regressions within the photic zone. Equations (1.1), (1.2) and (1.3) are used effectively to compute the per cent contribution of the downwelling irradiance profile, $\Delta \bar{E}_{d}(z)$, the upwelling irradiance profile, $\Delta \bar{E}_{u}(z)$, and the surface downwelling irradiance, $\Delta \bar{E}_{S}\left(0^{+}\right)$, respectively:

$$
\Delta \bar{E}_{d}(z)=(0.1695 z+14.535) \int_{400}^{700} E_{d}(z, \lambda) \mathrm{d} \lambda
$$

$$
\begin{gathered}
\Delta \bar{E}_{u}(z)=(0.4373 z+25.401) \int_{400}^{700} E_{u}(z, \lambda) \mathrm{d} \lambda \\
\Delta \bar{E}_{s}\left(0^{+}\right)=(9.11) \int_{400}^{700} E_{s}\left(0^{+}, \lambda\right) \mathrm{d} \lambda .
\end{gathered}
$$

So that the directional shortwave flux over 300-700 nm can be calculated as

$$
\begin{aligned}
\bar{E}_{N}(z) & =\int_{300}^{700} E_{N}(z, \lambda) \mathrm{d} \lambda \\
& \equiv \int_{400}^{700} E_{N}(z, \lambda) \mathrm{d} \lambda+\left[0.01 \Delta \bar{E}_{N}(z)\right] .
\end{aligned}
$$

$E_{N}$ may be substituted by $E_{s}$ (i.e., $z=0^{+}$), $E_{d}$ or $E_{u}$ profiles from Satlantic observations. The Satlantic measured 
upwelling radiances, $L_{u}(z, \lambda)$, were multiplied by a Q-factor $\left(=\frac{E_{u}}{L_{u}} \approx 4.5\right)$ to obtain the upwelling irradiance profiles (Morel and Gentili 1991, 1993). All integrations were performed using the MATLAB ${ }^{\circledR}$ trapezoidal scheme. Prior to integration, all SPMR/SMSR irradiance spectra were interpolated to $1 \mathrm{~nm}$ wavelength using cubic splines (de Boor 1978).

\subsection{Ancillary measurements}

The profiler also carried ancillary sensors-a WetSTAR fluorometer that measures the Chl- $a$ fluorescence, a thermistor to measure the water temperature, and a Viatran pressure transducer to estimate the pressure converted depth. A significant underestimation of the Chl- $a$ concentration measured by the WetSTAR fluorometer has been found (Raman pers. comm.). Nevertheless, the relative accuracies of concentrations are adequate for the purpose of this study. To overcome the absolute accuracies, all Chl- $a$ data were normalized to the cruise maximum.

\section{Results}

Radiant heating of the upper ocean due to the absorption of sunlight by seawater and biogenous matter can be determined form the net irradiance spectrum (Ivanoff 1977, Morel 1988, Seigel et al 1995), which is defined as

$$
E_{n}(z, \lambda)=E_{d}(z, \lambda)-E_{u}(z, \lambda),
$$

where, $E_{n}, E_{d}$ and $E_{u}$, respectively, are the net irradiance, downwelling (measured) and upwelling (estimated) irradiances. The apparent changes in the net irradiance below the water surface is observed as rapid attenuation occurs in wavelengths greater than $600 \mathrm{~nm}$. Below a depth of $10 \mathrm{~m}$, the contribution of longer (red) wavelengths to the net irradiance is negligible (less than 5\%). Thus the total net irradiance at greater depths can be attributed to the blue-green regions of the solar spectrum (with a peak at $\sim 490 \mathrm{~nm}$ ). The surface flux and net solar radiation flux at each depth from the Satlantic data are calculated by integrating the net irradiance over the wavelength range $400-700 \mathrm{~nm}$ as

$$
\left.\bar{E}_{n}(z)\right|_{400} ^{700}=\int_{400}^{700} E_{n}(z, \lambda) \mathrm{d} \lambda .
$$

The net penetrating solar flux from the net irradiance spectrum over 300-700 nm, $\bar{E}_{n}(z)$, was then corrected using equation (2). The transmission function, $T_{r}(z)$, for penetrating solar radiation within the upper ocean, which gives the amount of energy available at any depth for a given surface energy, is the total net solar flux normalized by the total incident flux at the surface

$$
T_{r}(z)=\frac{\bar{E}_{n}(z)}{\bar{E}_{s}\left(0^{+}\right)} .
$$

Figure 3 represents the SK190 cruise mean transmission function, $\left\langle T_{r}(z)\right\rangle$, which follows an ideal near-exponential decay of the net flux with depth (Jerlov 1976). More than $50 \%$ of the surface flux is absorbed within the top $5 \mathrm{~m}$. Thus, if the incident flux and the transmission function are known, the net solar flux profile can be retrieved from equation (5).

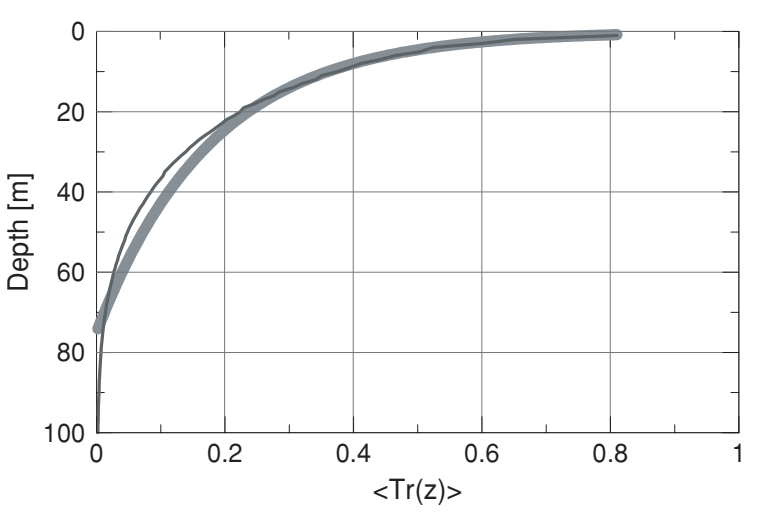

Figure 3. Cruise mean transmission function, $\operatorname{Tr}(\mathrm{z})$; the grey thick line shows the exponential fit to the mean transmission curve.

Table 2. Cruise mean transmission function, and Radiant heating rates at different depths during the operation period.

\begin{tabular}{lllll}
\hline $\begin{array}{l}\text { Depth } \\
(\mathrm{m})\end{array}$ & $\begin{array}{l}\left\langle T_{r}(z)\right\rangle \\
(\%)\end{array}$ & $\begin{array}{l}\left\langle E_{n}(z)\right\rangle \\
\left.(\mathrm{W} \mathrm{m})^{-2}\right)\end{array}$ & $\begin{array}{l}\text { Layer } \\
(\mathrm{m})\end{array}$ & $\begin{array}{l}\left\langle\left[\partial T_{z} / \partial t\right]_{\mathrm{rad}}\right\rangle \\
\left({ }^{\circ} \mathrm{C} \mathrm{day}^{-1}\right)\end{array}$ \\
\hline 10 & 35.84 & 101.435 & $0-10$ & 0.17918 \\
20 & 21.97 & 062.170 & $10-20$ & 0.11280 \\
30 & 14.07 & 039.835 & $20-30$ & 0.08412 \\
40 & 08.96 & 025.365 & $30-40$ & 0.07003 \\
50 & 05.32 & 015.059 & $40-50$ & 0.05844 \\
60 & 03.15 & 008.922 & $50-60$ & 0.05336 \\
\hline
\end{tabular}

Radiant heating rate for an upper layer ocean (from surface to a depth $z$ ) in the upper ocean is a function of the net solar flux just below the surface, $\bar{E}_{n}\left(0^{-}\right)$, and the net flux at that depth, $\bar{E}_{n}(z)$. Relating the rate of energy absorption to the rate of change of temperature, the radiant heating rate may be calculated from the first law of thermodynamics

$$
\left[\frac{\partial T_{z}}{\partial t}\right]_{\mathrm{rad}}=\frac{\bar{E}_{n}\left(0^{-}\right)-\bar{E}_{n}(z)}{\rho_{w} C_{p} z},
$$

where, $\rho_{w}$ is typical seawater density $\left(\sim 1025 \mathrm{~kg} \mathrm{~m}^{-3}\right)$ and $C_{p}$ is the specific heat of seawater at constant pressure (4100 $\mathrm{J} \mathrm{kg}^{-1}{ }^{\circ} \mathrm{C}^{-1}$ ). The net flux just beneath the surface layer can be approximately obtained from the net incident surface flux as $\bar{E}_{n}\left(0^{-}\right)=(1-\alpha) * \bar{E}_{s}\left(0^{+}\right)$, where the sea surface albedo $(\alpha)$ is 0.06 (Payne 1972).

Our discrete observations during the entire cruise span almost equally from morning till evening (figure 4). Hence the cruise mean net penetrating flux counts for the diurnal cycle of the intensity of the solar energy. The mean day time incident flux at the ocean surface during SK190, $\left\langle E_{S}\left(0^{+}\right)\right\rangle$, was $308.5 \mathrm{~W} \mathrm{~m}^{-2}$. Table 2 summarizes the cruise mean transmission function at different depths and radiant heating rate of different layers in the upper ocean in the ASWP region. The unprecedented radiant heating rates for the ASWP domain, computed from the in situ observations, are comparable to those found by Seigel et al (1995) in the western Pacific warm pool.

Time variation of the surface Chl- $a$ and temperature is shown in figure 5. During the study period, a deep chlorophyll maximum (DCM) was found at around 60-80 m depth which is shallower than the summer monsoon (June-September) 


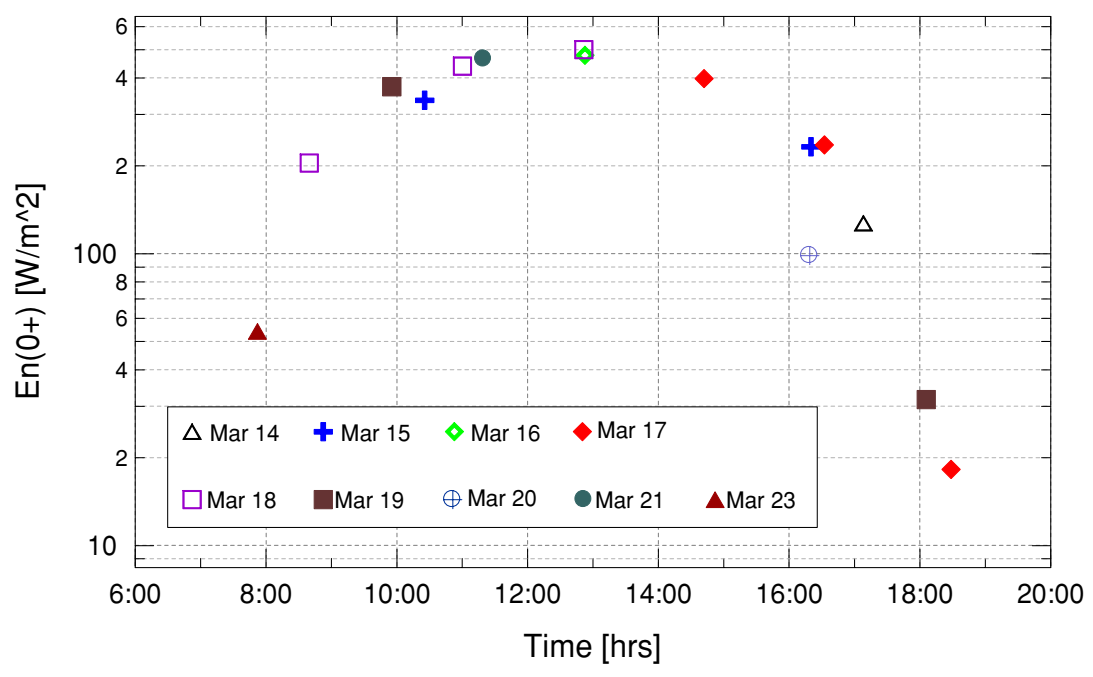

Figure 4. Above surface net flux over the entire operation at different times of the day during the entire cruise.
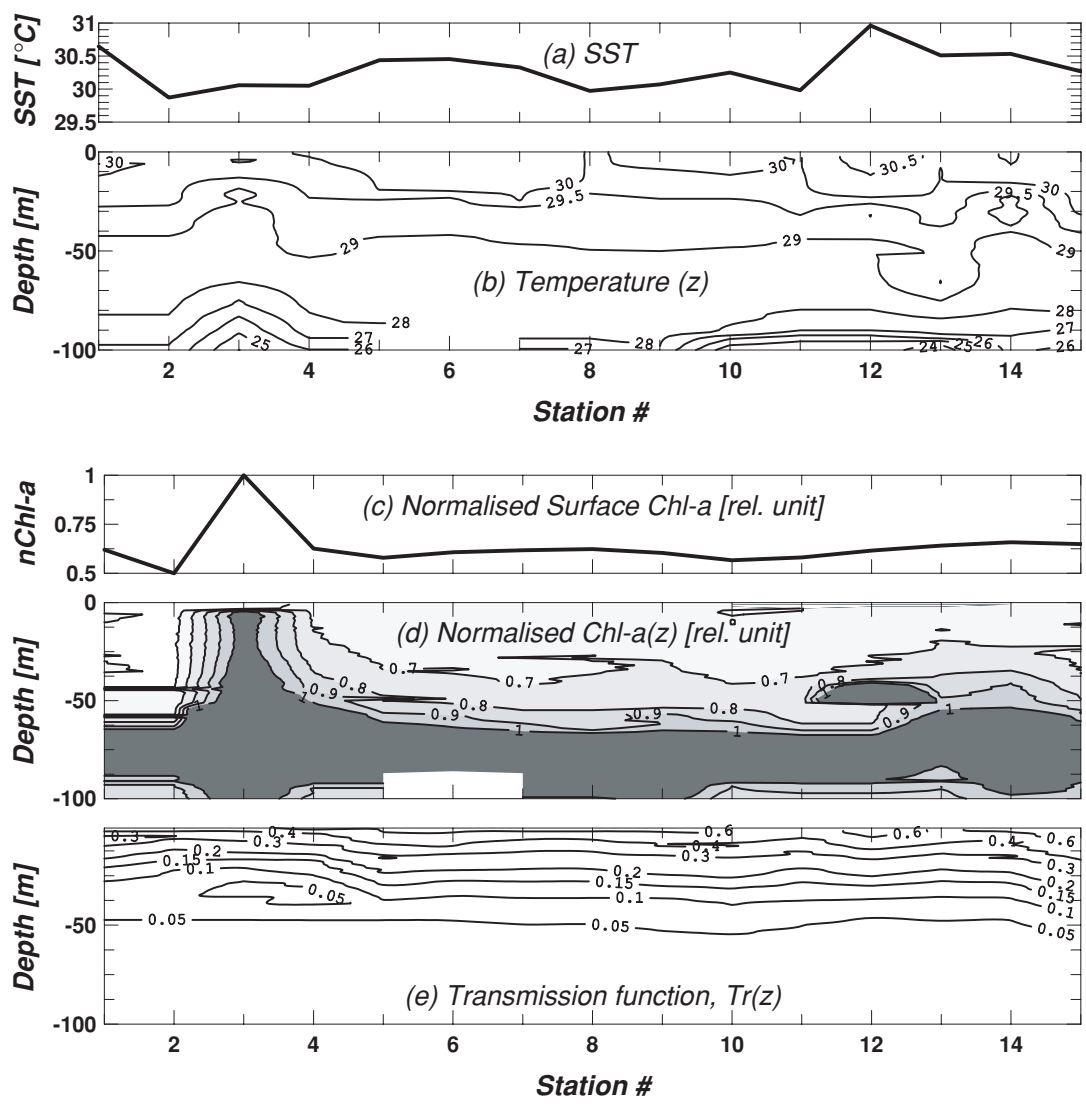

Figure 5. Surface and depth profiles of temperature $(a),(b)$, chlorophyll- $a(c),(d)$, and transmission function $(e)$ for the entire cruise period. The chlorophyll values are normalized with the maximum value obtained during the entire cruise.

mixed layer depth (MLD) in the Arabian Sea (Prasad 2004). The deepening of the MLD after the warm pool event is due to the strong wind-driven vertical mixing. There was no significant change in the Chl- $a$ concentration during this short observation except for station number 3 and $12-14$, where the DCM was found at shallower depths. There was a significant fall in SST by $0.9^{\circ} \mathrm{C}$ (figure 5) between stations 1 and 2 accompanied with cooling down to $\sim 100 \mathrm{~m}$ depth, associated with an increase in the Chl- $a$ concentration. There was also a corresponding decrease in the MLD (estimated approximately from the temperature profile) from station 1 to station 2. The cooling and the increase in the Chl- $a$ is probably because the ship moved into a region with an increased Chl- $a$ concentration and a different thermal structure (see below). The OCM snapshot on 15 March reveals an eddy and traces of high chlorophyll concentration at its periphery (figure 6). This picture coincides with the in situ surface chlorophyll high on 15 March at station 3 as the Chl- $a$ concentration in OCM 


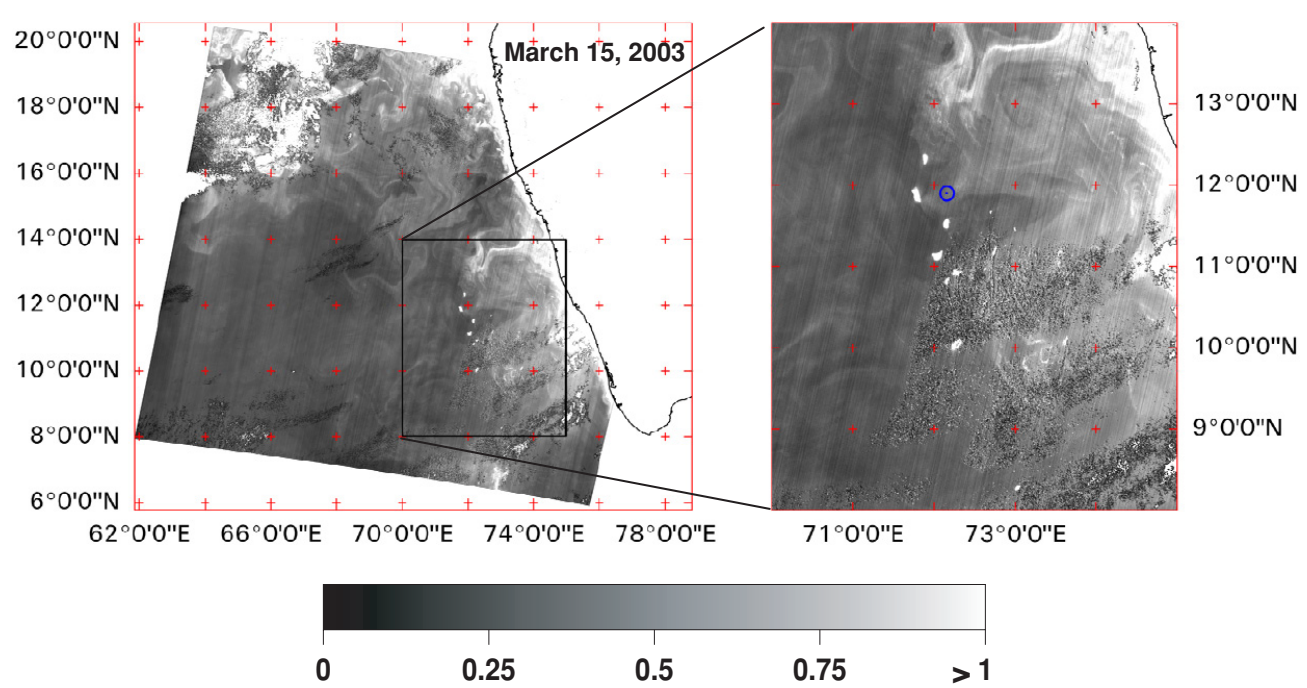

Figure 6. OCM derived Chl- $a$ concentration over the south-eastern Arabian Sea. Right panels show the blow-up region (box in the left panel) with the point showing the location of station $3(72.20 \mathrm{E} / 11.87 \mathrm{~N})$.

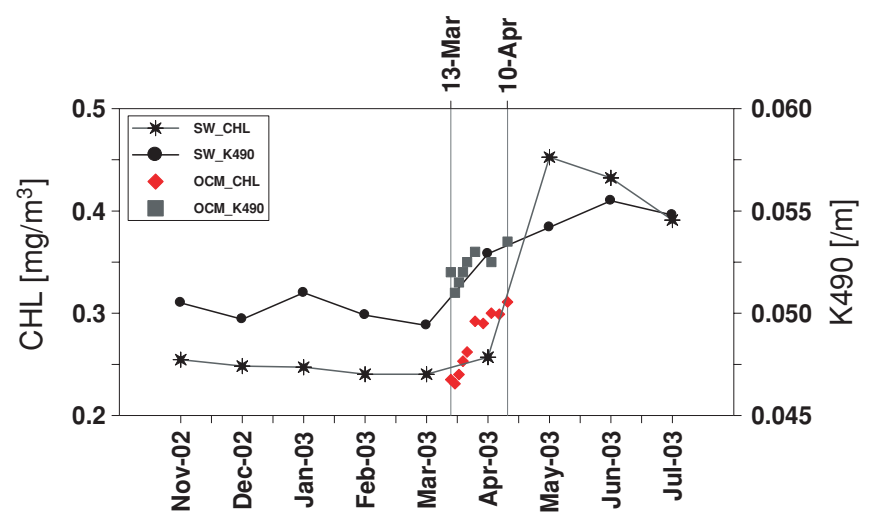

Figure 7. Time evolution of spatially averaged Chlorophyll- $a$ concentration and light attenuation at $490 \mathrm{~nm}$ (K490) over the ASWP domain. The lines in the graph represent monthly values taken from the SeaWiFS standard product. The solid diamonds and squares correspond to the OCM derived Chl- $a$ concentration and K490 for the cruise period.

images are around $0.5-0.7 \mu \mathrm{g} \mathrm{l}^{-1}$, which is higher than normal in open ocean (case 1) waters. Hence cooling and enhanced Chl-a concentration may be attributed to the eddy-induced vertical upwelling and injection of subsurface nutrients near station 3. An increase in the chlorophyll concentration is responsible for a reduction in the transmission of net solar radiation to depth (figure 5). The increase in the upper layer of the Chl- $a$ concentration resulted in a decrease in the penetrative radiation at stations $2-4$, which allows $\sim 10 \%$ of the surface energy down below the MLD ( $\sim 30 \mathrm{~m})$ (table 2$)$. Figure 7 shows the time evolution of the spatially averaged $\left(70^{\circ}-\right.$ $\left.77^{\circ} \mathrm{E} / 6^{\circ}-14^{\circ} \mathrm{N}\right)$ satellite derived Chl- $a$ concentration and light attenuation coefficients at $490 \mathrm{~nm}$ (K490) around the study area from November 2002 to July 2003. A clear increasing trend in the surface chlorophyll and light attenuation are seen from March until May 2003. Although in situ measurements were obtained for a short period, the results are significant showing the possible coupling between the upper layer biological and physical processes and most importantly a baseline for the ASWP heating rates.

\section{Discussion and conclusion}

This experiment was targeted to understand the upper layer thermodynamics of the Arabian Sea Warm Pool and to quantify the radiant heating rates during the pre-onset of the southwest monsoon with the aid of novel optical instruments. About $14 \%$ of the total incident shortwave flux penetrates into the mixed layer $(30 \mathrm{~m})$, which eventually result in a heating rate of $0.08{ }^{\circ} \mathrm{C}$ day $^{-1}$ in the $20-30 \mathrm{~m}$ water slab. Warming rate in the surface $10 \mathrm{~m}$ is about $0.18^{\circ} \mathrm{C}_{\text {day }^{-1}}$. In addition to this, satellite ocean colour data are quite useful to understand the bio-physical coupling over large dynamic areas. Since remotely-sensed ocean colour information are not just the surface manifestation (the pigment concentration retrieved by means of remote ocean colour sensors is a value representative of the upper metres of the water column i.e., the first attenuation depth), they can be treated as important components of the upper ocean dynamics. This work also suggests that biogenic matter can have a significant influence on the absorption of sunlight (in $300-700 \mathrm{~nm}$ wavelength domains) as a function of depth in the upper ocean. The trapped solar energy eventually enhances the radiant heating rates within the upper layers of the ASWP developing a shallow MLD before the onset of summer monsoon period (transition), when the impact of the wind-induced mixing is minimum. So the enhanced chlorophyll concentration could increase the heating rates until May although inter-annual variability cannot be ruled out.

The present study demonstrates the importance of solar penetration and in warm pool thermodynamics based on a small dataset collected during ARMEX-II. Nevertheless, further field observations of subsurface solar radiation together with optical and biological measurements are needed to understand the interrelationship between the radiant heating and phytoplankton. 


\section{References}

Baker K S and Frouin R 1987 Relation between photosynthetically available radiation and total insolation at the ocean surface under clear skies Limnol. Oceanogr. 32 $1370-7$

de Boor C 1978 A Practical Guide to Splines (New York: Springer)

Godfrey J S and Lindstrom E J 1989 The heat budget of the equatorial western pacific surface mixed layer J. Geophys. Res. 94 8007-17

Ivanoff A 1977 Oceanic absorption of solar energy Modelling and Prediction of the Upper Layer of the Ocean ed E B Krauss (New York: Pergamon) pp 47-71

Jerlov N G 1976 Marine Optics (New York: Elsevier) pp 229

Morel A 1988 Optical modeling of the upper ocean in relation to its biogenous matter content (case I waters) J. Geophys. Res. 93 10749-68
Morel A and Gentili B 1991 Diffuse reflectance of oceanic waters: its dependence on sun angle as influenced by the molecular scattering contribution Appl. Opt. 30 4427-38

Morel A and Gentili B 1993 Diffuse reflectance of oceanic waters. II. Bidirectional aspects Appl. Opt. 32 6864-79

Mueller J L and Austin R W 1993 Ocean optics protocols. NASA Tech. Memo 104566545

Payne R E 1972 Albedo of the sea surface J. Atmos. Sci. 29 959-70

Prasad T G 2004 A comparison of mixed layer dynamics between the Arabian Sea and Bay of Bengal: One-dimensional model results J. Geophys. Res. 109 C03035, doi:10.1029/ 2003JC002000.

Raman M 2003 Personal communication

Seigel D A, Ohlmann J C and Washburn L 1995 Solar radiation, phytoplankton pigments and the radiant heating of the equatorial Pacific warm pool J. Geophys. Res. 100 4885-91

Smith R C and Baker K S 1978 Optical classification of natural waters Limnol. Oceanogr. 23 260-7 


\section{Queries}

(1) Author: Please provide keywords. 